\title{
APLIKASI STOCK OPNAME PRODUK KECANTIKAN KOSÉ BERBASIS ANDROID
}

\author{
Sausan Nada Yumnahadi ${ }^{1}$, Rouli Doharma ${ }^{2}$ \\ ${ }^{1,2}$ Sistem Informasi, Sekolah Tinggi Manajemen Informatika dan Komputer (STMIK) Widuri Jakarta, Indonesia \\ Correspondence email: rouly.doharma@gmail.com
}

Article history: $\quad$ Submission date: Okt 05, $2020 \quad$ Revised date: Nov 07, $2020 \quad$ Accepted date: Nov 17, 2020

\begin{abstract}
Stock opname is an effort to control the turnover of a product so as not to deviate. The implementation of stock opname is inseparable from the support of the information system, therefore the aim of this study is to analyze the stock opname process of KOSÉ beauty product and to create a suitable application to facilitate the process. Analysis performed using the System Development Life Cycle. Data collection was obtained through interviews, observations, sampling and literature. The application design uses the Object Oriented Programming method. Testing application uses the blackbox method. The results of this study are an android application is made through Kodular and connected to the realtime database of Firebase, but the implementation of the application still has flaws in logic block-coding.
\end{abstract}

Keywords: Stock Opname, Android, Realtime Database, Kodular.

\begin{abstract}
ABSTRAK
Stock opname merupakan salah satu upaya untuk mengendalikan perputaran sebuah produk agar tidak menyimpang. Pelaksanaan stock opname tersebut tidak terlepas dari dukungan sistem informasi, oleh sebab itu tujuan dari penelitian ini adalah untuk menganalisa proses bisnis stock opname produk kecantikan KOSÉ dan membuat aplikasi yang sesuai untuk memudahkan proses tersebut. Analisa yang dilakukan menggunakan metode System Development Life Cycle. Pengumpulan data didapatkan melalui wawancara, pengamatan, pengambilan sampel dan studi pustaka. Perancangan aplikasi menggunakan metode Object Oriented Programming. Metode pengujian yang digunakan melalui blackbox testing. Hasil penelitian ini berupa sebuah aplikasi berbasis android yang dibuat melalui Kodular dan terhubung dengan realtime database Firebase, namun dalam penerapan aplikasi masih memiliki kekurangan pada logic block-coding.
\end{abstract}

Kata Kunci: Stock Opname, Android, Realtime Database, Kodular.

\section{PENDAHULUAN}

Pada pelaksanaan distribusi produk KOSÉ harus memiliki Sistem Pengendalian Intern (SPI) untuk menjamin kebenaran setiap proses perputaran produk yang dilakukan. Salah satu fungsi dari Sistem Pengendalian Intern tersebut adalah dengan diadakannya pelaksanaan Stock Opname (SO) secara berkala. Penerapan stock opname produk kecantikan KOSÉ dilakukan secara langsung menggunakan mata dan hitungan jari, dimana setiap penjumlahan stok produk didasarkan pada nama produk yang dituliskan ke dalam form stock opname. Hal ini menyebabkan kredibilitas data stock opname menjadi kurang akurat dan memerlukan perhitungan ulang yang memakan waktu lebih banyak.
Selain itu, untuk mendapatkan hasil stock opname produk kecantikan KOSÉ belum bisa dilakukan saat eksekusi stock opname berlangsung dikarenakan sistem komputerisasi yang sedang berjalan belum mempunyai fungsi yang mendukung proses pencocokkan data stock opname secara lansung ditempat (Husain \& Doharma, 2017).

Dalam rangka mewujudkan pelaksanaan stock opname produk kecantikan KOSE yang akurat, efektif, efisien, terarah dan terbuka, diperlukan sebuah aplikasi yang bisa bergerak dimana saja dan kapan saja. Oleh karena itu, pemanfaatan fungsi teknologi smartphone berbasis android bisa dijadikan alternative sebagai tools barcode scanner dengan menggunakan kamera pada smartphone. Dimana, teknologi tersebut berupa sebuah aplikasi yang memproses hitungan stok fisik dengan cara men-scan setiap barcode produk KOSÉ di counter penjualan. 
Dibandingkan dengan alat barcode scanner pada umumnya, pemanfaatan teknologi smartphone ini lebih praktis untuk dibawa kesetiap counter penjualan produk KOSÉ dan tidak membutuhkan biaya yang tinggi.

Tujuan dari penelitian ini adalah untuk merancang sebuah aplikasi stock opname produk kecantikan kose berbasis android guna memperoleh informasi stok fisik produk yang benar dan dapat dipercaya (Sudarsono et al., 2019).

Penelitian dari Edwin Yulia Setyawan dengan judul Automasi Stock Opname BMN Melalui Pemindaian $Q r$ Code Menggunakan Aplikasi Visual Basic For Application. Dengan menggunakan sistem automasi ini, dapat meningkatkan efektivitas dan efisiensi pengelolaan barang milik negara, yang meliputi pelaksanaan stock opname, pencatatan perubahan data nama dan spesifikasi barang, pemegang barang dan status barang, pelaporan hasil stock opname yang digunakan sebagai sumber perubahan data Barang Milik Negara dan databasenya menggunakan microsoft excel (Setyawan, 2019).

Penelitian dari Asep Saepulloh dan Mohammad Adeyadi dengan judul Aplikasi Scanner Berbasis Android Untuk Menampilkan Data Id Card Menggunakan Barcode. Dengan adanya aplikasi ini dapat memudahkan pengguna untuk men scan Id card supaya mengetahui biodata pemilik Id card dan barcode scen bisa digunakan oleh smartphone android (Saepulloh \& Adeyadi, 2019).

Penelitian dari Michael Christian Wibisono, Agustinus Noertjahyana, dan Andreas Handojo. Dengan Judul Pembuatan Aplikasi Pencatatan Stock Dengan Menggunakan Barcode Pada Android. Dengan adanya aplikasi ini dapat melakukan download data stock barang dan aset dari server tergantung otorisasi, dapat memindai barcode dengan menggunakan kamera yang terdapat pada mobile device untuk melakukan pencataan barang, dapat melakukan pencatatan jumlah stok barang dan aset pada periode tertentu,dan terdapat laporan pencatatan stock barang dan aset pada periode tertentu dan pada penelitian ini aplikasi dibangun menggunakan zxing, eclipse, sqlite, json, dan rest (Wibisono et al., 2013).

Berdasarkan penelitian yang terdahulu, keterbaharuan dalam penelitian ini adalah aplikasi stock opname produk kecantikan KOSE menggunakan layanan database milik google yang digunakan secara realtime dan merupakan cloudhost database. Selain itu aplikasi yang dibangun menggunakan web creator Kodular dan berfokus hanya pada pemindaian barcode produk bukan $Q R$ Code dan penelitian saat ini berfokus untuk menampilkan informasi lengkap produk dan jumlah stock produk yang dipindai.
Dari penjelasan diatas maka penulis ingin merancang dan membuat sebuah aplikasi stock opname produk kecantikan kose berbasis android untuk mempermudah dan mempercepat informasi stok fisik produk.

\section{METODE PENELITIAN}

Pengumpulan data pada aplikasi stock opname produk kecantikan KOSE berbasis android dilakukan dengan menggunakan wawancara, pengamatan, pengambilan sampel dan studi pustaka yang terkait dengan penelitian sebelumnya.

( Budiyantara et al., 2020).

Analisa perancangan aplikasi dengan metode berorientasi objek atau object oriented programming, yaitu terdiri dari: use case diagram, activity diagram, sequence diagram, statechart diagram, class diagram, entity relationship diagram (Sani \& Wiliani, 2019).

Sedangkan pembuatan prototype user interface aplikasi menggunakan software mockup Balsamiq Wireframes. Bahasa pemrograman yang digunakan adalah block coding dari web creator Kodular dan database yang digunakan adalah Firebase (Pusparini et al., 2020).

Metode Pengujian (testing) aplikasi menggunakan metode blackbox. Untuk mempermudah studi literatur dalam perancangan aplikasi stock opname produk kecantikan KOSÉ berbasis android. Kerangka pemikiran dalam penelitian ini dapat dilihat pada gambar 1 dibawah ini: (Wiranata et al., 2020).

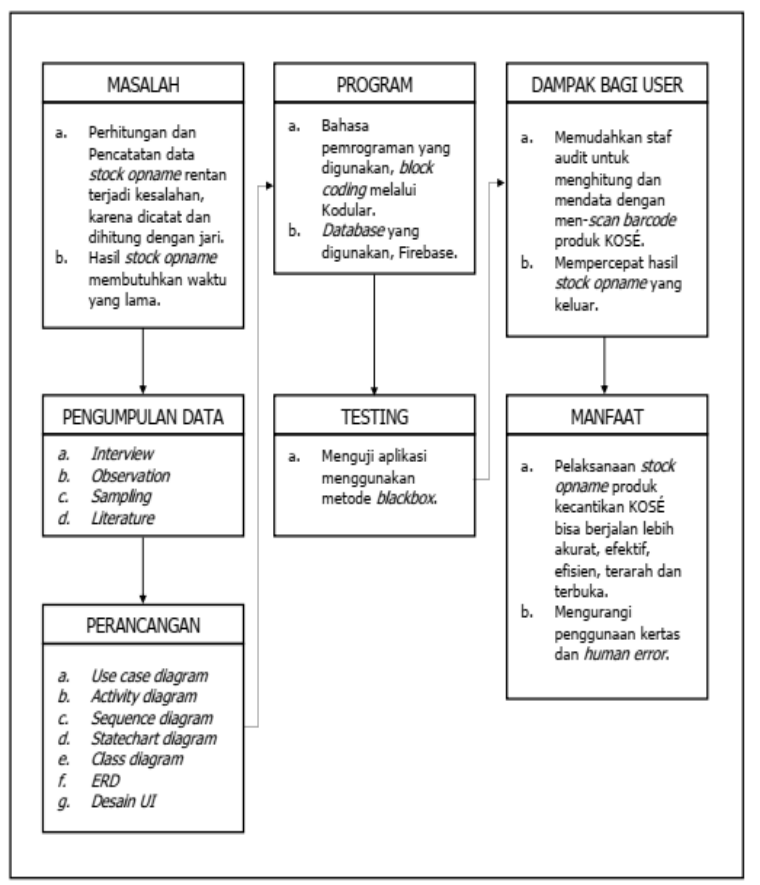

Sumber: (Yumnahadi., 2020)

Gambar 1. Kerangka Berfikir Penelitian 
Didalam kerangka berfikir terdapat permasalahan dari penelitian yang dilakukan, metode pengumpulan data yang dilaksanakan, membuat perancangan aplikasi, membuat program aplikasi, melakukan testing pada aplikasi, dampak pembuatan aplikasi bagi user, dan Manfaat bagi user atau pengguna.

\section{HASIL DAN PEMBAHASAN}

\section{Analisa Kegiatan Stock Opname}

Proses Mengelola Fisik

Pada proses ini, setiap produk KOSÉ yang terdapat di counter penjualan akan diperiksa satu persatu kondisi produk tersebut dan dihitung jumlah kuantiti masing-masing produk. Kemudian jumlah hitungan ditulis kedalam form stock opname dan ditanda-tangani oleh Beauty Advisor (BA) (Mahdiana, 2011).

Proses Kalkulasi Data

Pada proses ini dilakukan untuk mengetahui hasil Stock Opname (SO). Hasil SO didapatkan dengan cara export data excel stock quantity per period terlebih dahulu, kemudian input angka hitungan fisik yang ada di form SO kedalam excel, Selanjutnya, angka SO dengan angka stok quantity per period dibandingkan dengan rumus yaitu:

Hasil SO = Angka SO - Stock Qty Per Period ...

Proses Penyesuaian Data

Hasil SO yang sudah diketahui akan disortir berdasarkan barang tertukar, barang hilang, dan barang lebih. Lalu ditelusuri kembali melalui Stock Card Quantity. Masing-masing barang tertukar, hilang atau lebih akan dibuat kedalam form tersendiri, form barang tertukar, form barang hilang, dan form barang lebih. Form-form tersebut sebagai bukti sah untuk diproses oleh staf EDP menjadi data penyesuaian dalam Sistem ABS. Setelah seluruh penyesuaian data dilakukan, maka akan ditetapkan sejumlah denda yang ditangguhkan kepada BA yang bersangkutan. Dan terakhir akan dibuatkan sebuah Laporan Stock Opname sebagai referensi adanya pemotongan gaji dari denda stock opname.

\section{Use Case Diagram Sistem Berjalan}

Pada keseluruhan proses bisnis stock opname produk kecantikan KOSE yang sedang berjalan dapat digambarkan melalui use case diagram, sebagai berikut:

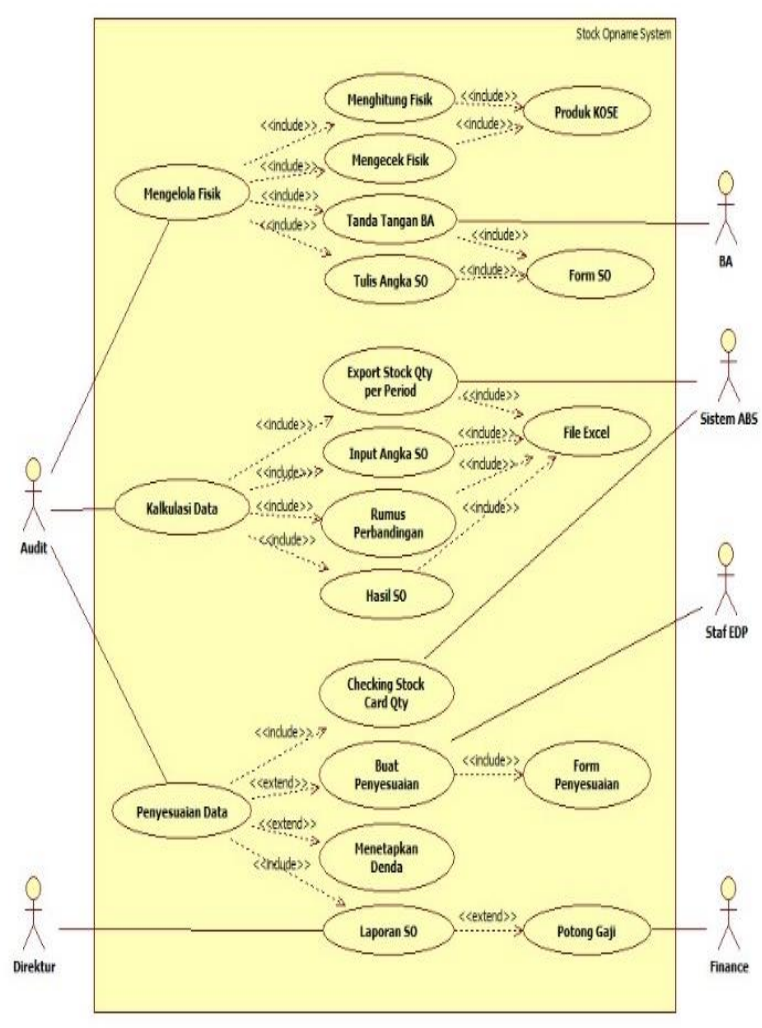

Sumber: (Yumnahadi, 2020)

Gambar 2. Use Case Diagram Sistem Berjalan

\section{Use Case Diagram Rancangan Aplikasi}

Use case diagram pada rancangan aplikasi stock opname produk kecantikan KOSÉ berbasis android yang dibangun, dapat dilihat pada gambar dibawah ini:

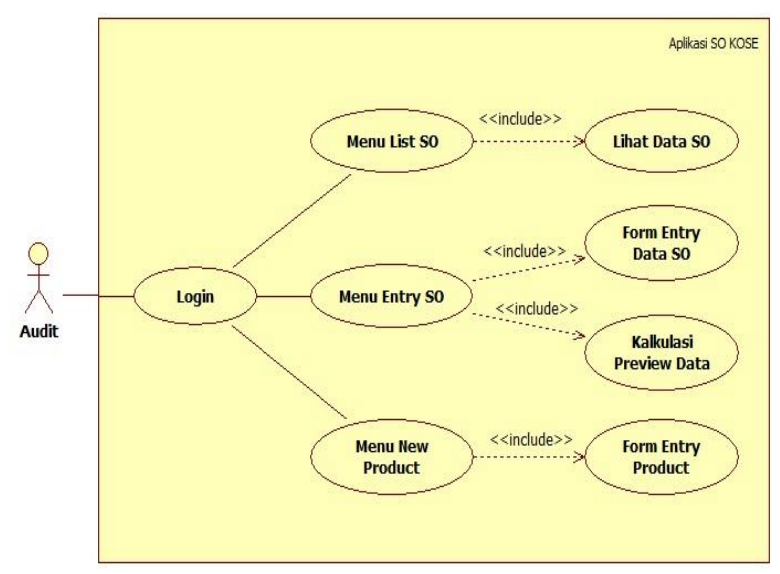

Sumber: (Yumnahadi, 2020)

Gambar 3. Use Case Diagram Rancangan Aplikasi

\section{Activity Diagram Rancangan Aplikasi}

Activity diagram pada rancangan aplikasi stock opname produk kecantikan KOSÉ berbasis android yang dibangun, sebagai berikut: 


\section{Activity Diagram Menu Entry SO}

Berikut adalah aktivitas menggunakan Menu Entry SO pada rancangan aplikasi stock opname produk kecantikan KOSÉ berbasis android yang digambarkan melalui activity diagram, yang dapat dilihat pada gambar dibawah ini:

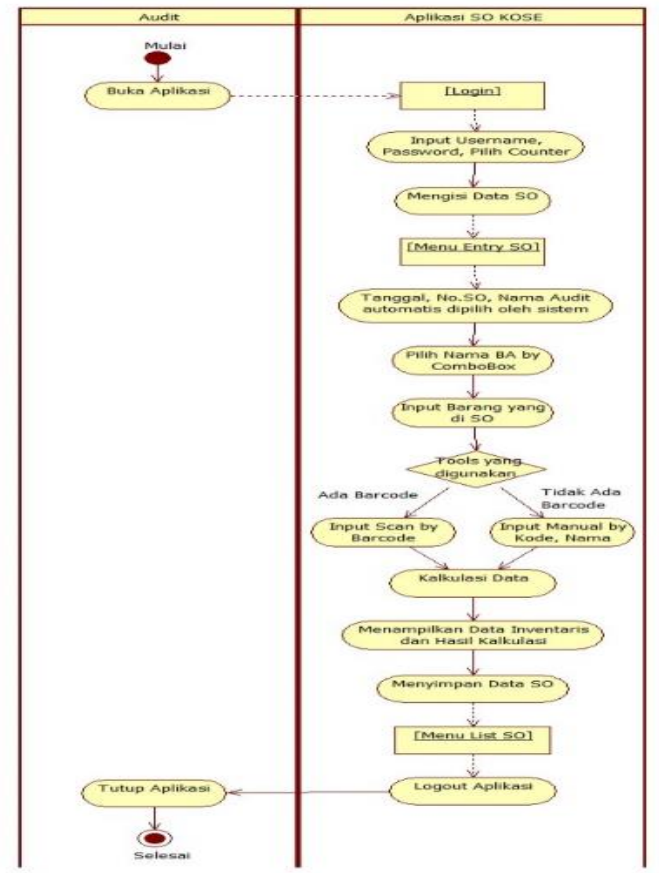

Sumber: (Yumnahadi, 2020)

Gambar 4. Activity Diagram Menu Entry SO

\section{Activity Diagram Menu List SO}

Berikut adalah aktivitas menggunakan Menu List SO pada rancangan aplikasi stock opname produk kecantikan KOSÉ berbasis android yang digambarkan melalui activity diagram, yang dapat dilihat pada gambar berikut ini:

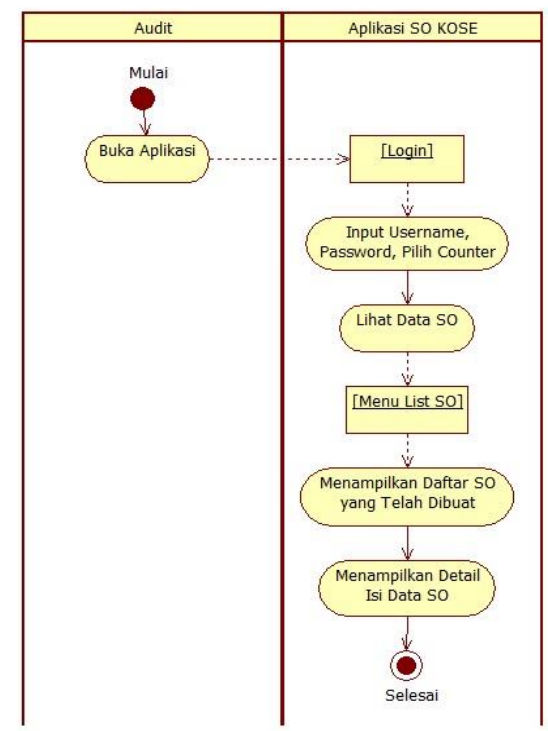

Sumber: (Yumnahadi., 2020)

Gambar 5. Activity Diagram Menu List SO

\section{Class Diagram Rancangan Aplikasi}

Class diagram pada rancangan aplikasi stock opname produk kecantikan KOSÉ berbasis android yang dibangun, sebagai berikut:

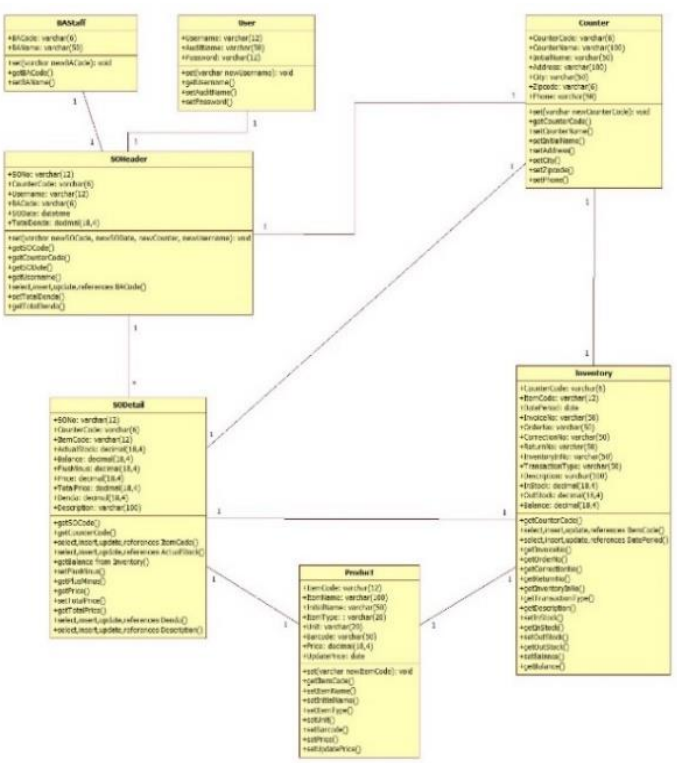

Sumber: (Yumnahadi, 2020)

Gambar 6. Class Diagram Rancangan Aplikasi

\section{Tampilan Login}

Pada halaman login terdapat logo, text input, dan tombol yang terdiri antara lain:

Pertama Logo kose, sebagai identitas aplikasi produk kose. Kedua text input username, untuk memasukkan identitas user yang mengakses aplikasi. Ketiga text input password digunakan untuk memasukkan kunci keamanan akses aplikasi.

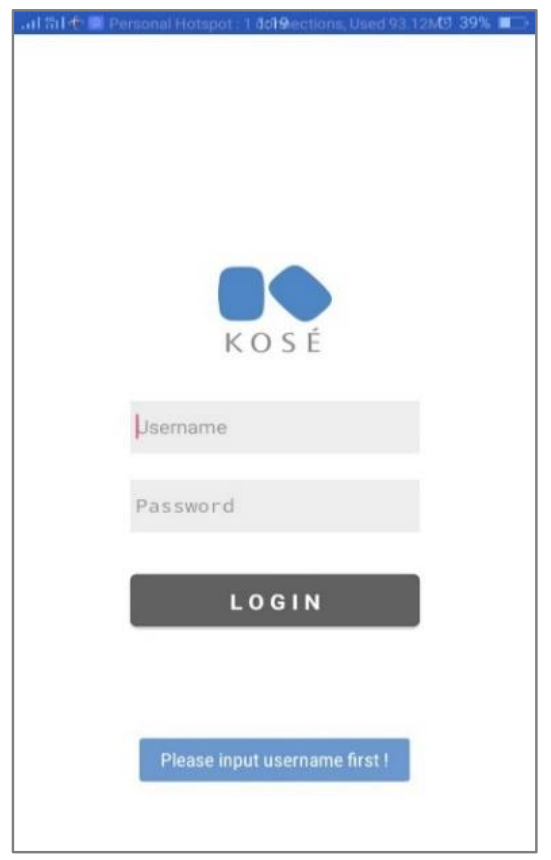

Sumber: (Yumnahadi, 2020)

Gambar 7. Tampilan Login 


\section{Tampilan Menu Home}

Pada halaman menu home terdiri dari:

Pertama logo KOSE, sebagai identitas aplikasi produk KOSE. Kedua Label text User-nim, sebagai informasi pengguna yang login aplikasi. Ketiga label text hari dan Tanggal, pengaturan hari dan tanggal secara automatis berdasarkan waktu login. Keempat Icon Entry SO, tombol untuk menampilkan form entry data SO. Kelima Icon List SO, tombol untuk menampilkan layar list data SO. Keenam Icon New Product, tombol untuk menampilkan form entry produk baru. Dan ketujuh Icon Logout, tombol untuk keluar akses aplikasi.

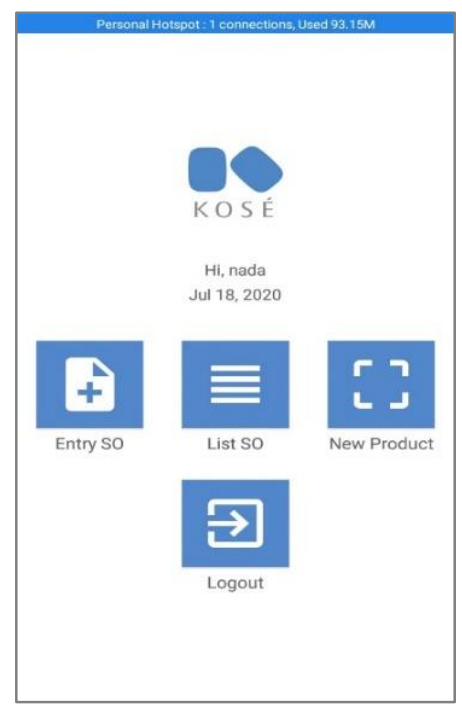

Sumber: (Yumnahadi, 2020)

Gambar 8. Tampilan Menu Home

\section{Pengujian Aplikasi}

Pengujian aplikasi stock opname produk kecantikan kose berbasis android menggunakan black box testing. Pada login aplikasi dan menu home dapat dilihat pada tabel 1 sebagai berikut:

Tabel 1. Pengujian Blackbox

\begin{tabular}{|c|c|c|}
\hline $\begin{array}{c}\text { Nama } \\
\text { Pengujian }\end{array}$ & $\begin{array}{c}\text { Kondisi } \\
\text { Pengujian }\end{array}$ & Hasil Pengujian \\
\hline \multirow[t]{3}{*}{$\begin{array}{l}\text { Form } \\
\text { Login }\end{array}$} & $\begin{array}{l}\text { Jika Username } \\
\text { dan Password } \\
\text { tidak diisi } \\
\text { kemudian user } \\
\text { menekan tombol } \\
\text { login. }\end{array}$ & $\begin{array}{l}\text { Sistem akan } \\
\text { menampilkan } \\
\text { notifikasi "User- } \\
\text { name is invalid" }\end{array}$ \\
\hline & $\begin{array}{l}\text { Jika username \& } \\
\text { password diisi } \\
\text { tetapi salah. }\end{array}$ & $\begin{array}{l}\text { Sistem akan } \\
\text { menampilkan } \\
\text { notifikasi } \\
\text { "Password } \\
\text { wrong" }\end{array}$ \\
\hline & $\begin{array}{l}\text { Jika username \& } \\
\text { password diisi } \\
\text { dengan benar. }\end{array}$ & $\begin{array}{l}\text { Sistem akan } \\
\text { menampilkan } \\
\text { screen home menu }\end{array}$ \\
\hline
\end{tabular}

\begin{tabular}{lll} 
Menu & Jika menekan & Sistem akan \\
Home & form entry Data & menampilkan \\
& Fo & Sorm Entry Data \\
& & \\
& Jika menekan List & Sistem akan \\
Data SO. & menampilkan List \\
& Data SO \\
& Jika Menekan & Sistem akan \\
Form Entry & menampilkan \\
Product. & Form Entry \\
& Produk \\
& Siktem akan \\
Icon Button & menampilkan \\
Logout & peringatan Logout \\
& dalam dialog box, \\
& dan menampilkan \\
& Screen Login \\
& setelah pilihan \\
\hline Sumber: (Yumnahadi, & 2020) \\
&
\end{tabular}

\section{KESIMPULAN}

Kesimpulan yang diperoleh dari penelitian ini yaitu, dengan aplikasi stock opname, perhitungan dan pencatatan data produk KOSE yang sedang di stock opname bisa dilakukan hanya dengan memindai barcode produk satu-persatu, sehingga bisa mengurangi kesalahan manusia apabila hanya menggunakan mata dan hitungan jari dan data yang didapatkan pun menjadi lebih akurat. Selain itu, Audit bisa mendapatkan hasil stock opname saat itu juga setelah semua barcode produk selesai dipindai, sehingga dengan adanya aplikasi stock opname ini membuat efektif dan efisien waktu pekerjaan audit. Aplikasi yang dirancang masih memiliki kekurangan dikarenakan terdapat kendala dalam logic block-coding Kodular dimana data dalam database Firebase tidak bisa dipanggil, sehingga menyebabkan beberapa kebutuhan dan tujuan penelitian belum terpenuhi.

\section{DAFTAR PUSTAKA}

Ade Davy Wiranata, \& Irwansyah, Agus Budiyantara, A. S. (2020). Employee Candidate Selection Using the Saw and Topsis. 3(1), 22-35.

Agus Budiyantara, Irwansyah, Egi Prengki, P. A. P. (2020). Komparasi Algoritma Decision Tree, Naive Bayes Dan K-Nearest Neighbor Untuk Memprediksi Mahasiswa Lulus Tepat Waktu. 
Husain, T., \& Doharma, R. (2017). Analisis dan Perancangan Sistem Informasi Recruitment Calon Tenaga Kerja Anak Buah Kapal di PT . Lakemba Perkasa Bahari. Kalbiscentia, 4 No 1, 21-28.

Mahdiana, D. (2011). Analisa Dan Rancangan Sistem Informasi Pengadaan Barang Dengan Metodologi Berorientasi Obyek : Studi Kasus $\mathrm{Pt}$. Liga Indonesia. Jurnal TELEMATIKA MKOM, Vol.3 No.2, September 2011 ISSN 2085-725X, 3(2), 36-43.

Pusparini, N. N., Budiyantara, A., \& Lusa, S. (2020). PENGARUH KNOWLEDGE MANAGEMENT SYSTEM UNTUK JENJANG JABATAN. 4(1), 80-88.

Saepulloh, A., \& Adeyadi, M. (2019). Aplikasi Scanner Berbasis Android Untuk Menampilkan Data ID Card Menggunakan Barcode. Jurnal Manajemen Dan Teknik Informatika, 03(01), 101-110.
Sani, A., \& Wiliani, N. (2019). Faktor Kesiapan Dan Adopsi Teknologi Informasi Dalam Konteks Teknologi Serta Lingkungan Pada Umkm Di Jakarta. JITK (Jurnal Ilmu Pengetahuan Dan Teknologi Komputer), 5(1), 49-56. https://doi.org/10.33480/jitk. v5i1.616

Setyawan, E. Y. (2019). Automasi Stock Opname Bmn Melalui Pemindaian QR Code Menggunakan Aplikasi Visual Basic For Application. 5(2), 125-137.

Sudarsono, B. G., Karno, U. B., \& Sihotang, M. (2019). Using PLS-SEM and Interpretative Analysis for Testing Questionnaire of The Success of Information Systems Strategic Planning Benefit Realization Using PLS-SEM and Interpretative Analysis for Testing Questionnaire of The Success of Information Systems Stra. July.

Wibisono, M. C., Noertjahyana, A., \& Handojo, A. (2013). Pembuatan Aplikasi Pencatatan Stock Dengan Menggunakan Barcode Pada Android. Jurnal Infra, 1(2), 1-4.

Yumnahadi, S. N. (2020). Aplikasi Stock Opname Produk Kecantikan KOSÉ Berbasis Android. 